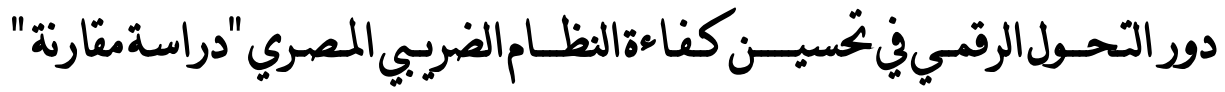 \\ د. مهاب محممد مححمـد إبراهيم زيدان \\ دكتـوراه في الاقتـصـاد والمـاليــة العـامــة
}

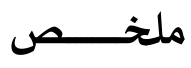

شهدت منظومة الإدارة الضريبية ثورة من التطوير، وجرى تنفيذ إصلاحات تاريخية تقود إلى توسيع القاعدة

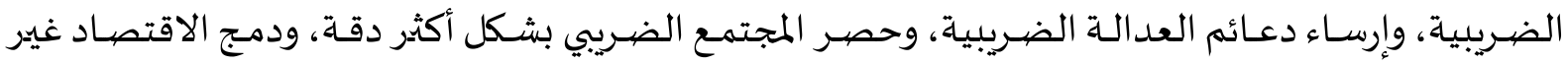
الرسـي في الاقتصـاد الرسـي، على النحـو الذي أسههم في زيـادة الإيرادات الضـريبية خلال السـنوات الأخيرة، بمـا

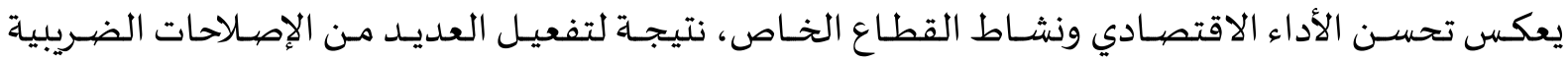

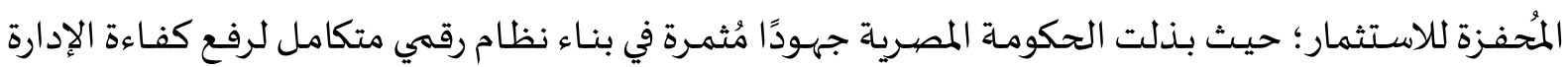

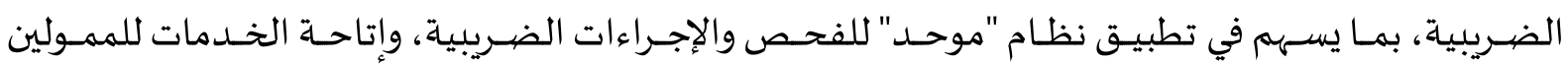
إلكترونيًا دون الحاجــة للـذهاب إلى المأموريـات. وترتكـز هـــه الجهـود على إطـارين أسـاسـيـين يتعلقـان بتطـوير السياسـات الضيريبية والإدارة الضريبية، وما يتضـمنه ذلك من محاور فرعيـة، مثل تطوير التشريعات والقوانين المتعلقة بالضـرائب، وميكنـة إجـراءات السـداد والتحصيل، وتطبيق التحـول الرقهى من خـلال منظومـة الفـواتير والإقـرارات الضــيبية الإلكترونيـة، وتطـوير البنيـة التحتيـة ومقـار مصـلحـة الضـرائب، وتنميـة قـدرات العنصــر

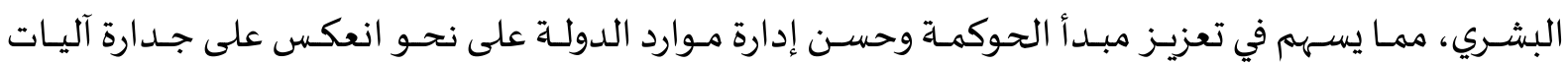
تحصيل الإيرادات الضريبية. كما تناولت هذة الدراسـة العديد من التجارب العالميـة والعربية على كيفية رقمنـة النظام الضريبي. 


\section{أولاً: مقـدمـــــة}

تمضسي الدول المتطورة بخطى سباقة نحو تبني التقنيات الرقمية، مثل الخدمات السحابية والبيانات الضخمة وتحليلها، بما يشجع الدول النامية على أن تحذوا حذوها، والتي وصلت إلى قناعـة بأن التحـول الرقمي أمـر ضـروري لا مفر منـه لكي تكون في الصـدارة، أو السير في الطريق الصـحيح نحوهـا، ولا شـك أن إدراكها لأهميـة هذه القوى الجديدة في عـالم الأعمـال، والتكيف معها، سـيعزز ازدهارهـا ونموهـا، في حين أن إغفالها ذلك وفثـلها في التكيف مـع المتغيرات سيهدد وجودها.

كعَ إلا أن هذه التقنيات الرقمية تمثل تحديًا كبيراً بالنسبة للكثير من الدول، والتي تعاني من صعوبة اللحاق بركب الثورة الرقمية وتعويض ما فاتهم، وعلى غرارهم الدول النامية، التي تشهر تراجعًا في المجال الرقمي بصفة عامة.

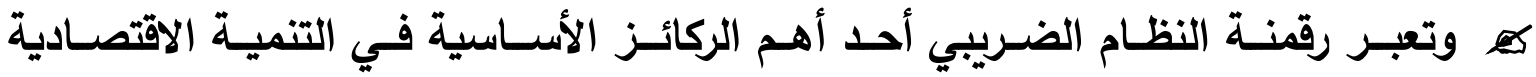
والاجتماعيـة مـن أجل مواجهـة التحولات الكونيـة المتسـارعة. وبالتـالي فرضـت على الحكومـات تحسين جودة الخدمات الضريبية واستخدام البيانات العامة والثخصية؛ وأيضًا دعم تطوير تطبيقات الذكاء الاصطناعي. وبالتـالي فرقمنـة النظام الضـربي يسـاهم بثكل أو بأخر في زيـادة الفعالية والكفاءة عن طريق ضبط المصالح الضريبية للعائدات الإضـافية بأقل جهد وفي وقت أقل ممكن، وعليـه فقد سـاهمت رقمنـة الضـرائب في مصـر على إعطلاء دفعـة قويـة شكلت خيـار إسـراتيجي أساسي يسعى لترسيخ الثكل الجديد من الإدارة الإكترونية الحديثة، وتجاوز الطابع التقليدي من الإجراءات الضريبية المعول بها وجعل الثكل الجديد من الإدارة الإلكترونية أكثر مرونة ودقة. كعِ فسياسـة التحديـث والتجـديد التي تتهجها الـدولة المصرية للتغلب على العـيا من المشاكـل الضـريبية أصـبحت متجـاوزة في ظل رقمنـة الإدارة الضـريبية، والإنخراط في التحـول الرقمي الذي فرضته العولمة والانفتاح على السوق الحرة. حيث أتاحت الرقمنـة الضريبية الفرصـة للكثف عن التهرب الضـريبي، والتخفيف من حجم العبء على الموظفين المكلفين بالضـريبة، وحرصـت على الالتزام التـام بأداء الواجب الضـريبي لــلإدارة الضـريبية، والمسـاهمة في ترسـيخ 
الثفافية والمساواة بين جميع المواطنين دون استثناء. وبالتالي فالحديث عن رقمية النظام الضريبي وأثره على تحقيق العدالة الضريبية أصبح من الموضوعات الضرورية الملحة. كهِ يث تمضـي الدولـة المصـرية بخطى ثابتـة في تنفيذ المشروع القومي لتحديث وميكنة منظومة الإدارة الضريبية، وذلك من أجل تبسيط وتوحيد وميكنة الإجراءات الضريبية؛ بما يُسهم في التيسير على المدـولين، وحوكمـة المجتــع الضـريبي، ومكافحـة الفسـاد، وإرسـاء دعـائم العدالـة الضريبية، وتوفير الضمانات الكافية لاستيداء حق الدولة، والحد من الاقتصساد غير الرسمي، على النحـو الذي يُسـاعد في تحقيق المسـتهدفات الماليـة والاقتصـادية، وتمكين الدولـة مـن اسـتكمال مسيرتها التنموية، والوفاء بالتزاماتها نحو المواطنين، حيث إن هذا المشروع يرتكز على المنظومة الضريبية الأساسية إضافة إلى الإقرارات الإلكترونية، والفاتورة الإلكترونية، والإيصال الإلكتروني. كعِ أن مشروع التحول الرقمي بمصلحة الضرائب لايمكن اختزاله في مجرد ميكنة الإجراءات، بـل يمتـد الأمـر إلىى إرسـاء دعـائم منظومـة ضـربيية متكاملـة من خـلال إعـادة هندسـة الإجراءات وتبسيطها، وتطوير الغطاء التشريعي والتنفيذي، وتتمية الوعي الضريبي لاى المواطنين والممولين، وتأهيل الكوادر البشرية، بمراعاة التدرج في التطبيق والتهيئة المبكرة لمجتمع الأعمال وتوفير الدعم الفني المتكامل.

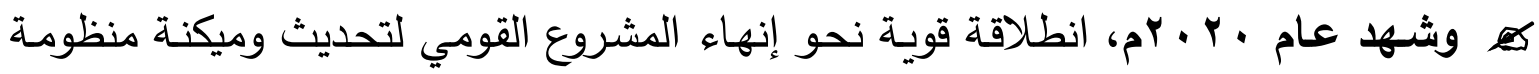
الإدارة الضـربية، الذي يحظى بدعم كبير ومتابعـة دقيقة من القيادة السياسية، ويستهدف إرسـاء دعائم منظومـة ضريبية أكثر تطورًا، تكون محفزة للاستثمار وترتكز على ترسيخ جسور الثقة مع الممولين؛ باعتبارهم اشركاء التميةه،، وترتقي بمصر لمصاف الدول المتقدمة. 
كعِ يهـدف التحـول الرقـي إلى رفـع كفــاءة الإدارة الضـرببية عن طريق تبسيط الإجراءات على الممولين، والعاملين بالمصلحة، وإتاحة أحدث تكنولوجيا رقمية متطورة في الأعمال الضريبية من خـلال موظفين أكفاء، وهيكل تتظيمي مرحلي موحد يتناسب مـع أهداف التطوير ممـا يحقق زيادة فعالية التحصيل الضريبي، وتقليل تكلفة التحصيل. كهِ أيضًا زيـادة الحصيلة عن طريق حصر، ودمج الاقتصاد غير الرسمي، وتوسيع القاعدة الضـرببية، وإحكام السيطرة على التهرب الضـريبي الجزئي والكلي، وزيـادة فعاليـة التحصسيل عن طريق الوصول إلى العدد الأمثل من المأموريات الذي يؤدي إلى رفع درجات السيطرة، والإحكام على العمل الضريبي، وتعزيز ثقافة الالتزام الطوعي للمجتمع الضريبي. ثالـثًا: مشـكلــــة الدراســــــة

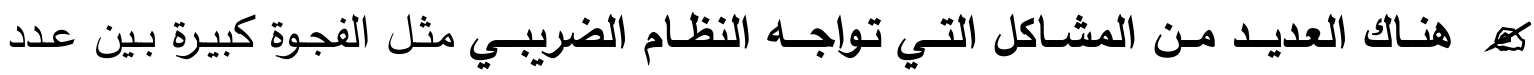
المسـلين ومقدمي الإقرارات الضـريبية، والتهرب الضـريبي فمثنلاً قاعدة البيانـات للقيمـة المضـافة تضم حوالي مائتن وعشـرين ألف ممول، بينما تضم قاعدة بيانات "ضريبة الدخل" ثلاثتة ملايين ممول، وبالبحث تبين أن مائسة وإثنين وتسعين ألفا فقط مسجلة، من بينهم مائهة وعشرون ألف حالة تقدمت بإقرار صفري (أي ليس عليه ضرائب)؛ وهو ما يشير إلى أن القيمة المضافة تقوم على سبعسين ألف ممول فقط، نصفهم أقل مما يقدره النظام وفق منظومـة الإقرارات الإكترونية علاوة على أن عشرين في المئة من الفواتير المقدمة وهمية، وأن هناك شركات متخصصسة في إصدار مثل هذه الفواتير الوهمية. أيضًا هناك العديد من المنشـآت غير مسجلة. كذلك هناك من يقوم بتحصـيل ضـرائب القيمـة المضـافة مـن المـواطنين ويمتنع عن توريـدها إلى الخزانـة العامـة 
ISSN 2537_0715

IJSRSD (2021): Volume 4, Issue 2, July 2021

Received: June 2021, Accepted: July 2021
International Journal of Scientific Research and Sustainable Development

\section{رابعَا: خطـــة الدراســــــة:}

المبحثث الأول: مـاهيــة التحـول الرقمــي.

المطلب الأول: مفهوم التحـول الرقــي وأهدافــــ.

$$
\text { المطلب الثـاني: معوقـات التحـول الرقـمي وسبـل التغـلب عليهـا. }
$$

المبـحث الثاني: رقمنــة المنظومـة الضـريبيـة ودوره في تعزيز كفـاءة النظام الضريبـي.

المطلب الأول: الفواتيـر الضريبيـة الإلكترونيـة كأحـد الأدوار المؤسسية لرقمنـة الضرائـب.

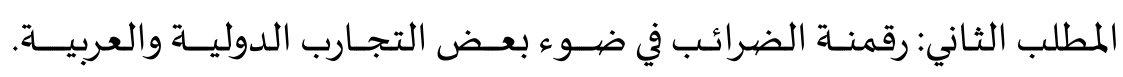




\section{المبــــــ الأول

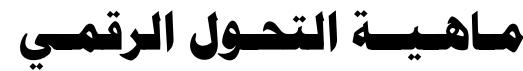

تمهييد وتقسيم:

كعِ أثرت التحولات الرقمية غير المسبوقة التي يشهدها العالم على كافة مناحي الحياة، والتي أسفرت عن تحقيق مكاسب كبيرة على صعيد الإنتاجية والتتافسية من خلال دورها في إعادة تشكيل طريقة أداء العديد من القطاعات الإنتاجية والخدمية، كما انعكست كذلك على آليات عمل وأداء السياسات الاقتصادية الكلية ومن بينها المالية العامة، امتدادًا لهذه التحولات وفي إطار الثورة الصناعية الرابعة وما صاحبها من تقنيات مثل الأكاء الصناعي، والبيانات الكبيرة، وسلسلة الكتل (البلوك شين)، والتقنيات الحيويـة وغيرها من التقنيات الأخرى.

كهِ و وقد اتجهت العديد من الحكومات للاستفادة من هذه التقنيات في زيادة مستويات فاعلية إدارة الماليـة العامـة في تحقيق أهدافها من خلال تطوير آليات أكثر كفــاءة لجمـع الأمـوال العامـة وانفاقها بما يحقق أهداف السياسـة الماليـة.

كهِ تتطرق رقمنة المالية العامسة للعديد من الجوانب من بينها التحول الرقمي علي صعيد إدارة جانبي الموازنة العامة (الإيرادات والمصروفات العامة) لاسميا من خلال تبني نظم التحصيل والدفع الإككتروني، فعلى صعيد جانب الإيرادات العامة، ساعدت رقمنة الضرائب العديد من الدول على زيادة مستويات التحصيل الضريبي، وتوسيع القاعدة الضريبية من خلال التحول للنظم الإلكترونية للإقرار والامتثال الضريبي والتحصيل والفوترة الإكترونية، فيما ساهمت رقمنة الإنفاق العام في زيادة كفاءة نظم المشتريات الحكومية، ومكافحة الفساد، وتحسين فاعلية نظم التحويلات الاجتماعية عبر إنشاء قواعد بيانات أكثر دقة لمن هم مؤهلون للحصول على الاعم، وتوجيه التحويلات النقدية إليهم عبر قنوات الدفع الإلكتروني بطريقة سهلة وآمنة، يمكن التحقق منها مثل الهواتف المحمولة باستخدام توقيع البصمة البيومتربة،، وبالتالي تمكين الحكومات من الوصول إلى قاعدة واسعة من المستفيدين بأقل كلفة. 


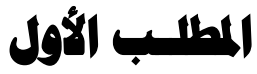

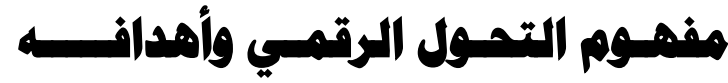

كهِ تواجه المجتمعات اليوم تحدي حضاري غير مسبوق لما تحدثه التكنولوجيات الرقمية من تحولات فائقة السرعة على المستوى الاقتصادي والثقافي والسياسي والمعرفي، وكذا على سلوكيات الأفراد وعلاقاتهم داخل المجتمعات( الأســرة، المجتمع المـدني....إلخ ) وعلي أشكال التتظيم والقيم الاجتماعيـة، وكثر الجدل حول التحول الرقمي وأهميته ومردوده على مستقبل المؤسسات الحكومية أو غير الحكومية.

$$
\text { أولاً: مفهوم التحول الرقمي: }
$$

كبع يثير مفهوم التحول الرقمي Digital Transformation إلى استخدام التكنولوجيا الرقمية والتطورات المصاحبة للثورة الصناعية الرابعة بمواقع التواصل الاجتماعي، من خلال استخدام الذكاء الاصطناعي، وتحليلات البيانات الكبيرة، والحوسبة السحابية وإنترنت الأشياء، مما أفسح المجال لظهور نماذج أعمال جديدة مثل المنصات الرقمية(1). كهِ وقد عرفت منظمـة التعـاون الاقتصادي والتنمية OCAD عام 2015 التحول الرقمي" بأنه النتيجة لعملية تحويلية جلبتها المعلومات وتكنولوجيا الاتصالات، التي جعلت التقنيات أرخص وأكثر قوة موحدة على نطاق واسع، وأدت إلى تحسين العمليات التجارية، وتعزيز الابتكار في جميع قطاعات الاقتصاد (2).

كen ويعرفه عبدالوهاب غنيم بأنها عملية انتقال وتحول المؤسسات الحكومية للعمل وفقًا لنماذج الأعمال (Business Models)، والتي تعتمد على التكنولوجيا الرقمية، والبنية التحتية المعلوماتية الذكية، والمبنية على المعرفة والابتكار والإبداع في تقديم المنتجات والخدمات للمتعاملين بكفاءة وفاعلية وبأسلوب آمن، ومن خلال وسائل تكنولوجية رقمية،مثل الهاتف المحمول والحاسبات الآلية وغيرها(3). 
كع كما يقصد بالرقمية إمكانية تحويل كافة أشكال وأنواع البيانات والمعلومات المكتوبة أو المسموعة أو المرئية، وسواء كانت تلك المعلومات في شكل صور أو أحرف أو أرقام، إلى شكل رقمي أساسه الصفر والواحد، ويمكن نقلها بين أجهزة الحاسبات من خلال الثبكات(4).

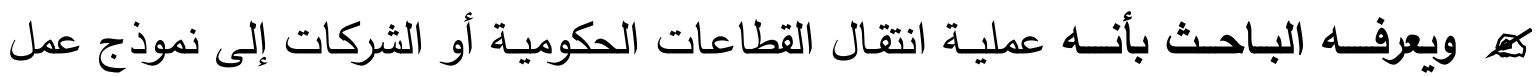
يعتمد على التقنيات الرقمية في ابتكار المنتجات والخدمات، وتوفير قنوات جديدة من العائدات التي تزيد من قيمـة منتجاتها.

كلِ و وبذلك فإن التحول الرقمسي يوضح كيفية استخدام التكنولوجيا داخل المؤسسات والهيئات سواء الحكوميـة أو القطاع الخـاص على حد سواء فهو يسـاعد على تحسين الكفاءة التشـيلية وتحسين الخدمات التي تقدمها للعمـلاء والجمهور المستهدف من تلك الخدمات، فهو يقوم على ركى توظيف التكنولوجيا بالثكل الأمثل مما يخدم سير العمل داخل المؤسسة في كافة أقسامها وأيضًا في تعاملها مـع العملاء والجمهور لتحسين الخدمات وتسهيل الحصول عليها مما يضمن توفير الوقت والجهد في آن واحد.

ثانيًا: مقومـات ومتطلبـات التحول الرقمي: 1- الجوانـب الأساسيـة والتي تثتمـل على ما يلـي (5): - البنيـة التحتيـة للأعمـال الإلكـترونية (شبكــات الإنتـرنت والاتصــالات). - الابتكارات الرقمية ( أشباه المواصلات والمعالجات). - التقنيات الأسـاسية ( أجهـزة الحاسب الآلي وأجهزة الاتصهالات السلكيـة واللاسلكيـة). 2- قطاعـات تكنولوجيا المعلومـات والقطاعات الرقميـة التي تتتج المنتجات الرئيسية أو الخدمات التي تعتمد على التقنيات الرقمية الأساسية (كالمنصات الرقمية والتطبيقات المحمولة وخدمات

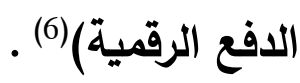
3- القطاعات الرقمية والتي تشتمل على المنتجات الرقمية وتستخدم الخدمات بشكل متزايـد كالتجـارة الألكترونيـة. 
كعِويأتسي التحول نحسو رقمنـة الماليـة العامـة في سيـاق " استراتيجيـة التنميـة المستدامـة لرؤيسة مصــر 2030"، والبرنـامج الـوطني للإصــلاح الاقتصـادي الـذي يتضــن حزمــة مـن الإصـلاحات الماليـة الراميـة لتحديث إدارة المالية العامـة، وتحسين تعبئَة الموارد، وتعزيـز كفاءة الإنفاق العام باستخدام التقنيات الرقمية(7). فعلى مستوى السياسـات المالية، عملت وزارة المالية على تحسين طريقة آداء الخدمات المالية بسهولة وكفاءة وفعالية، وتطبيق آليات الدفع والتحصيل الإلكتروني الحكومي، بالإضافة إلى تطوير طريقة إعداد الموازنة العامة للدولة في إطار منهجية البرامج والآداء، وكذلك تطوير النظم الضـريبية والإقرارات الضـريبية الرقمية، وتفعيل التحصيل الإلكتروني بكافة جهات الدولة والدفع الإلكتروني للمدفوعات الحكومية، بالإضافة إلى إنثاء النافذة الواحدة بالجمارك المصرية،وكتلك التحول الرقمي الخاص بنظم التعاقدات الحكومية، وذلك بهدف تحفيز بيئة الاستثمار على النحو الذي يُسهم في تعزيز بنية الاقتصـاد القومي وتعظيم الإيرادات العامـة للدولة، وتحسين الخدمات المقدمـة للمواطنين، وتقليـل الفسـاد (8).

كعِوعلى مستوى السياسات النقدية، فقد حقق البنك المركزي تطورًا هائلًا في سياسة الثمول المالي، بما يضمن تحقيق النمو الاحتوائي لكافة الفئات، ويساعد في دمج المنشآت الصغيرة من القطاع غير الرسمي داخل الهيكل الاقتصـادي الرسمي للدولة، ويضمن تطور الخدمة التي تقدمها المؤسسات المالية المدرجة في نطاقه لتوافر عنصر التتافسية بين المؤسسات، ويجنب الأفراد المخاطر العالية للخدمات المالية غير الرسمية، بالإضافة إلى دراسة إمكانية إصدار عملة رقمية

كِي أيضًا اتجهت الحكومسة المصريـة بداية من شهر يوليو 2018م إلى تحصيل الرسوم الضريبية والجمركية للمبالغ التي تزيد عن 5000 جنيه من خلال الوسائل الإكترونية عبر مركز الدفع الإكتروني والتحصيل التابع لوزارة المالية. وعلي صعيد آخر، استخدمت الحكومة نظام إدارة المعلومات المالية الحكومية لتنفيذ الموازنة العامة للدولة من أجل السيطرة على الإنفاق الحكومي، يساعد التكامل بين هذا النظام، وحساب الخزانة الموحدونظم الدفع الإكتروني، والوحدات المحاسبية التي تقوم بأعمالها من خلال تلك المنظومة عبر دورة الوثائق الإلكترونية على تثديد 
الرقابة الإلكترونية على وحدات المحاسبة، كذلك تقوم الحكومة المصرية حاليًا بصرف رواتب موظفي الجهاز الإداري بالدولة وأيضًا العاملين في جميع الوحدات المحاسبية الموازنة الدولة والهيئات الاقتصادية إلكترونية، حيث تم إصدار 4,9 مليون بطاقة إلكترونية لصرف مرتبات العاملين بالدولة، وسبع مليون بطاقة لأصحاب المعاشات.

كهِ ومن أجل زيـادة كفاءة المنظومة الضربيية تسعى وزارة المالية في إطار برنامج إصـلاح الإدارة الضـريبية إلـى بـدء التقديم الإلزامسي لإقرارات مقدمي الضـرائب لكل مـن ضـريبة القيمـة المضافة، وضرائب الاخل إلكترونية، وهو ما سيساعد على إثراء قاعدة بيانات الضرائب الخاصـة بالنشاط الاقتصادي(9).

كهِ الإكتروني مع استخدام قاعدة بيانات الكترونية واحدة، بما يضمن النزاهة والثفافية في سير العمل وتتشيط التجارة الخارجية، استكمالا المنظومـة رقمنـة المالية العامـة، أصدرت مصر قانون جديد للتعاقدات الحكوميـة في أكتوبر 2018م، حيـث تـم إطـلاق البوابـة الحكوميـة للمشتريات لتوفير احتياجات الوزارات المختلفة، كما تسعى وزارة الماليـة إلى إرسـاء منظومـة الفوترة الإلكترونيـة من خـلال العمل على إصـدار قانون منظم لذلك بمـا يسـاعد على تعزيز الحصـيلة الضـريبية ودمـج الاقتصاد غير الرسمي في الاقتصاد الرسمي، وهو ما سوف ينعكس إيجابيًا على الاقتصساد القومي ككل. 


\section{المطبد الثـاني}

\section{هموقـات التهول الرقمي وسبـل التغلبـ عليهــا}

$$
\text { أولاً: عدم وجود رؤيـة قوميـة متكاملة للتحول الرقمـي: }
$$

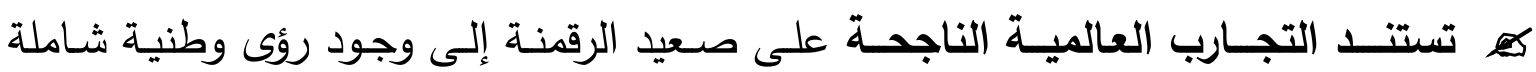
للتحول الرقمي وفق إطار تدريجي داعم لهذا التحول يضمن مشاركة كافة الأطراف المعنية، حسب جدول زمني واضـح يراعي توفير المنطلبات اللازمة والبنية الأساسية الداعمة لهذا التحول الثامل على مختلف الأصعدة والتي يمكن البناء عليها لمساعدة عمليات التحول الرقمي في القطاعات المختلفة وفق أطر تكاملية وأدوار محددة للجهات المعنية تضمن نجاح هذا التحول(10).

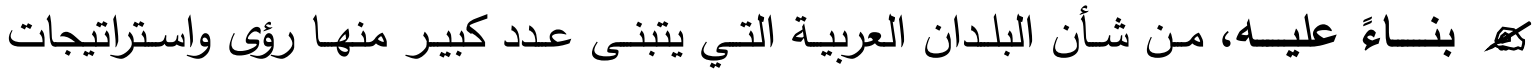
مستقبلية للتحول الرقمي الاستفادة من الزخم الذي تتيحه التقنيات المصاحبة للثورة الصناعية الرابعة في تطوير وزيادة مستويات كفاءة الأداء الاقتصادي بشكل عام وتحقيق نقلة في السياسات العامة وتقديم الخدمات الحكومية بما ينعكس إيجابا على رفاهية المواطنين. ثانيًا:الشمـول المالي أسـاس النجاح مبادرات رقمنة الماليـة العامة: كلع يقصد بالثمول المالي، إتاحة واستخدام كافة الخدمات المالية لرختلف فئات المجتمع من خالل القنوات الرسمية بما في ذلك الحسابات المصرفية والتوفير ، خدمات الدفع والتحويل، خدمـات التأمين، وخدمات التمويـل والائتمان (جانب الطلب ) لتفادي لجوء البعض إلى القنوات والوسائل غير الرسمية التي لا تخضع للحد الأدنى من الرقابة والإشراف ومرتفعة الأسعار نسبيًا مما يؤدي

$$
\text { إلى سوء استغـلال احتياجـات هؤلاء من الخدمات المالية والمصرفيـة(11). }
$$

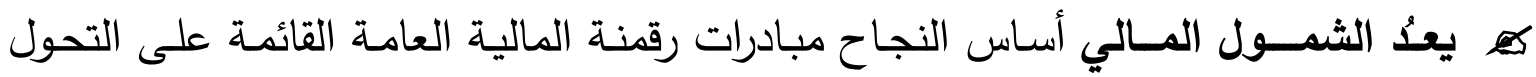
نحو نظم الدفع والتحصيل الإكتروني، فنفاذ السكان إلى هذه الخدمات الرقمية يتطلب وجود رؤية وطنية داعمة لزيادة مستويات الثمول المالي مع التركيز على المناطق المحرومة وتوفير التقنيات اللازمة لتسهيل هذا النفاذ بما يمكن من الاستفادة من اتجاه الحكومة لرقمنة المالية العامة ـ في 
هذا السياق، تشير الإحصـاءات إلى تواضـع نسبة نفاذ الأفراد والشركات في المنطقة العربية إلى الخـمات الماليـة والمصـرفية مقارنـة بالمتوسـط العـالمي والمستويات المسـجلة في بـاقي الأقـاليم الأخرى . كعِ لذلك تبدو الحاجة ملحة في عدد من البلدان العربية إلى تبني استراتيجيات داعمة للشمول المالي بالتركيز على زيادة الثمول المالي للثباب والإناث والسكان في المناطق النائية عبر تطبيق مجموعة من السياسات على جانبي العرض والطلب الخاص بالخدمات المالية والمصرفية(12). ثالثاً:مخاطر اختراق الخصيوصيية وسريـة البيانات ودعم الأمـن السيير انـي: كها ر رغم المكاسب الكبيرة التي تحققت على صعيد رقمنة المالية العامـة، تشير تجارب بعض الدول رغم ذلك إلى وجود بعض المخاطر التي ترتبط بهذا التحول وخاصـة فيما يتعلق بحالات الخروقات التي تعرضت لها هذه النظم وتم على أثرها انتهاك خصوصية وسرية بيانات المسجلين في بعضـها. ففي الولايـات المتحدة الأمريكية تمت سرقة البيانات من مصلحة الضـرائب ووزارة الخارجية بما أشار إلى ضعف النظم الحكومية. فيمـا تعرضت بعض الدول الأوروبية لعدد كبير مـن المطالبـات الاحتياليـة ، شـكلت في مجملهـا مطالبـات ضـخمة لاسـترداد ضــربية القيمـة المضافة(13). كذلك تعرض نظام الهوية الوطنية المطبق في الهند لعدد من الخروقات تم على إثرها تسريب أسـماء وعنـاوين وأرقـام الهويـة الوطنيـة وتفاصسيل الحسـابات المصـرفية لعدد 1,4 مليون متقاعد بطريق الخطأ مـن قبل مكتب الضـان الاجتمـاعي الحكومي. كمـا تمكن بعض البائعين المجهولين على تطبيق واتساب من بيع بعض البيانات الخاصة بعملاء النظام(14. كهيع وعليه، تتطلب التحولات الرقمية جهود مكثفة على مستوى السلطات الرسمية لإقرار الأطر التشريعية والتتظيمية والمؤسسية اللازمة الحماية سرية البيانات والخصوصية ودعم مستويات الأمن السيبراني بما يزيد من مستوى ثقة المتعاملين في الأنظمة المرتبطة برقمنة المالية العامـة ولاسيما على ضوء حجم المعاملات الضخم الذي يتم عبر هذه الأنظمة(15). رابعًا:القيود المؤسسية والقانونية وقيود القــدرات البشـرية: كهِ ت تستلـزم مبـادرات التحـول الرقمـي جهود حكوميـة لـدعم القـدرات المؤسسية والقانونيـة والكفـاءات البشـريـة المتوافرة في وزارات الماليـة ووحدات تتفيذ الموازنـة العامـة للدولتة. فمـن جهـة 
تتطلب عملية رقمنة المالية العامـة سن حزمـة من القوانين التي تنظم عمليات الدفع الإككتروني، ورقمنـة المشـتريات الحكوميـة، وغيرهـا مـن التشـريعات الداعمـة لهذا التحـول، إضـافة إلى بعض التغييرات المؤسسية والتظيمية التي يفرضها هذا النوع من أنواع التحولات. كذلك من المهم تطوير القدرات البشرية في وزارات المالية ووحدات تتفيذ الموازنـة العامـة بما يسمح بوجود رؤى واضـحة الماهية الإصلاحات المطلوبة على مستوى المالية العامة بشكل عام، وكيف يمكن لرقمنة المالية العامة أن تساهم في تنفيذ وزيادة كفاءة هذه الإصلاحات بشكل خاص وبدون وجود هذه الرؤى فلن تسهم رقمنة المالية العامة في تحقيق الأهداف المرجوة منها(16). خامسًا: الحاجة إلى دعم البنية التقنية: كما م العـديد مسن مبـادرات رقمنــة المالية العامـة تقوم على وجود بنيـة أساسية رقميـة داعمـة ولازمة لهذا التحول، من أبرزها اتساع نطاق انتشار تقنيات الاتصالات وتقنيات المعلومات لاسيما انتثـار اسـتخدام الهـاتف المحمـول والنفـاذ إلـى البنيـة الأساسـية الرقميـة، خاصــة في المنـاطق المحرومـة والنائية وهو مـا سوف يساعد الحكومات على تحقيق مكاسب كبيرة منم الاتجاه نحو رقمنة المالية العامة(17). سـادسَّــا:الأميــــــة التكنــولـوجيــــة: كما تعـد الأميـة التكنـولوجية أحـ أبـرز معوقـات التحول الرقمى الذى بدأتـه مؤخرا لتعظيم الاستفادة من التطور التقنى فى تقديم الخدمات للمواطنين والاعتمـاد عليها بشكل أساسىى فى التعاملات اليومية(18).

كهِ لألك تـواجه الكثيـر من الدول الناميـة العديد من التحديات تتمثل فى القضاء على الأمية التقليدية من جهة، والأمتين المعلوماتية والمعرفية من جهة أخرى، وهذا يتطلب بناء بيئة معرفية التى يجب أن تسـل وتشجع الفرد على اكتسـب مهارات التعلم والتدرب الذاتى المستدام مدى الحياة، مع التركيز على مراجعة ما تم تعلمه سابقاً ومعاودة التعلم. كعة وفى هذا السياق، يرى الباحث ضرورة مواجهة الأمية التكنولوجية، من خلال إبراز أهم المعوقات نحو التحول الرقمى لتعظيم الاستفادة من التطور التقنى فى تقديم الخدمات للمواطنين والاعتماد عليه بشكل أساسى فى التعاملات اليومية. 
ISSN 2537_0715

IJSRSD (2021): Volume 4, Issue 2, July 2021

Received: June 2021, Accepted: July 2021
International Journal of Scientific Research and Sustainable Development

كهِ كمـا يـري الباحث ضـرورة العمل على محو الأمية الإلكترونية والتكنولوجية من خلال بعض وسائل الإعلام، الأمر الذى يتطلب التركيز على وجود حملات موسعة لنشر ثقافة التحول الرقمى، فضلا عن القيام بتدريب مقدمى الخدمات على التطور التكنولوجى. سـابعًا:من أبـرزالمعوقـات التي تقابـل عمليـة التحول الرقمـي، هـوضــف الإنترنت: كهِ و ويـرى الباحث، ضرورة اتجاه الحكومات نحو الميزانية العامة القطاعية، فعلى سبيل المثال في ميزانيـة 2021م سوف نوجـه معظم الميزانيـة إلى التحول الرقمي وفي 2022م سيتم توجيـ معظم الميزانيـة إلى قطلاع الصـحة أو التعليم، وبـذلك نكون تطورنـا القطاعات بشكل كامل دون وجود أي نواقص.

ثامنًأ: تفـرض الثـورة الرقميـة على الأسـواق والمجـتمع والحكومـات تحـديات تتعلق بكيفيـة التأقلم مع التغيرا ت المسـتمـرة(19). 


\section{البمـث الثاني

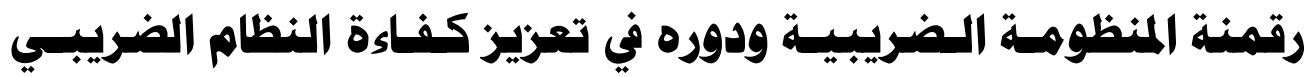

تمهييد وتقسيم:

كعِ يعـــ النظـام الإداري الضريبـي من الركائز الأساسية للتنميـة الاقتصـادية، وتسـاهم زيـادة كفاءة النظام الضـربي ووضـوحه في زيادة قدرة الحكومـة على تحصيل الإيرادات الضـرببية بأقل تكلفة، والحد من التهرب الضريبي. إضافة إلى ذلك، تساهم كفاءة النظام الضربي في تحسين بيئة الأعمال، الأمر الذي يساهم في جذب الاستثمار المحلي والاستثمار الأجنبي المباشر.

كها ع إحـى الآليـات التي تساهـم في زيادة تسهيل وتحسين الخدمات الضرببية وكفاءة النظام الضريبي هي رقمنة الضرائب. وتدل رقمنة الضرائب على التحول الرقمي لإدارة الضرائب(الإدارة الإلكترونية). وتعُد الرقمنة جزء من الجهود الحكومية لتطبيق الحوكمة الرقمية في تقديم الخدمات، واستخدام البيانات العامة والشخصية، ودعم تطوير تطبيقات الذكاء الاصطناعي ليتمم وظائف وأنشطة القطاع العام. 


\section{المطبدب الأول}

\section{الفواتيـر الـضريبية الإلكتزونيسة كأحس الأدوار المؤسسية لرقهنة الضرائب}

\section{أولاً:مفهـوم رقمنــة الضـــر ائب:}

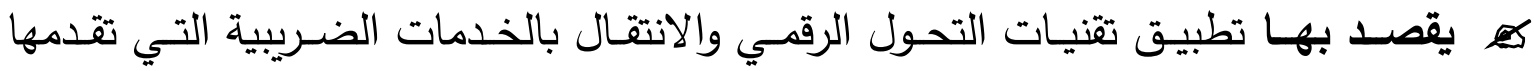
القطاعات الحكومية إلى نموذج عمل مبتكر يعتمد علي التتنيات الرقمية. وتعزز الأنظمة الضريبية المُعقَدة ثقافة التهرب الضريبي، وقد تهيئ الفرص للفساد، كما تثكل عبئا على قدرة الدولة في جمع المعلومات عن دافعي الضرائب، حيث أكدت بعض الدراسات ومنها دراسة مارسيلو استيفاو على أن انخفاض عدد المدفوعات الضريبية والوقت اللازم للامتثال للمتطلبات الضريبية قد يساهم في الحد من التهرب الضريبي، وتثجيع العديد من الأعمال في القطاع غير الرسمي على الانضمام إلى القطاع الرسمي. إضافة إلى ذلك، يساهم تسهيل الإجراءات الضريبيـة - التي تشمل رقمنـة

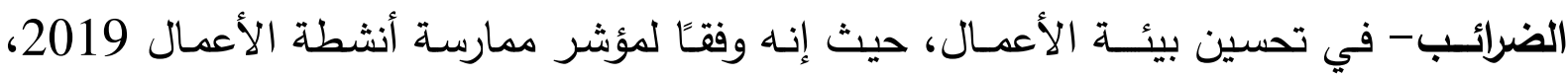
فإن أحد أهم أسباب رفع مرتبة مصر إلى 114 في 2019 من إجمالي 190 دولة بمجموع 6,1 نقطة من 100 نقطة من المرتبة رقم 128 في 2018 بمجموع 56,22 نقطة؛ هو تسهيل الدولة دفع الضرائب من خلال تطبيق نظام عبر الإنترنت لتقديم ودفع ضريبة دخل الثركات وضريبة القيمة المضافـة (20).

كهي يُعد قانـون الإجراءات الضريبيـة الموحد(*) رقم 206 لسنة 2020م نقلة تشريعية غير مسبوقة، إذ يستهف دمج وتبسيط وميكنة إجراءات ربط وتحصيل الضريبة على الدخل، والضريبة على القيمة المضافة، ورسم تتمية الموارد المالية للدولة، وضريبة الدمغة، وأى فرائض مالية ذات طبيعة مماثلة أو تتفق فى جوهرها مـع الضريبة؛ بما يُسهم فى بناء نظام رقمى متكامل، وإتاحة الخدمات للممولين أو المكلفين إلكترونيًا إضـافة إلى السداد الإلكترونى ، دون الحاجة للذهاب إلى المأموريات. 
كعِ وقد ساهمت هذه الجهود في تعزيز المراكز الضريبية للشركات بوضعها فى قائمة المخاطر الضريبية المنخفضة، وتبسيط إجراءات التسوية بين الثركات من خلال التبادل اللحظي لبيانات الفواتير المميكنة.

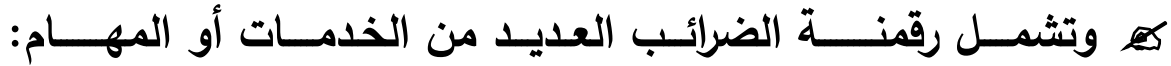
- استخدام النموذج الإلكتروني الموحد لتقديم الإقرارات الضريبية المطلوبة أو الاختيارية وبيانات الاخل الأخرى التي تشمل كثوف المرتبات. - إرسال بيانات المحاسبة أو مصادر أخرى لدعم الإيداعات مثل الفواتير وأرصدة المراجعة. - استخدام البيانات مثل الكثوف المصرفية في مطابقتها عبر أنواع الضرائب المختلفة. - توفير التدقيق الإلكتروني من قبل الجهات الحكومية. - توفير التقييم الإكتروني، والسماح لدافعي الضرائب بوقت محدود لتدقيق الضرائب المحسوبة من قبل الحكومة.

كمعا وتتمثل مـزايا الإدارة الإلكترونية في زيادة الشفافية، وانخفاض تكاليف جمع الضرائب، ومكافحـة التهـرب الضـرببي، وزيـادة الإيـرادات الضـريبية، ممـــيُسـاهم في كفـاءة وفاعليـة النظـام الضـريبي، وتعزيـز المسـاءلة التي ستسـاهم في انخفـاض الفسـاد، ورفع المسـاواة الضـريبية بـين الثـركات، وخلق منافسـة عادلـة بـين الثـركات، والقدرة على تبـادل المعلومـات، ومعرفـة الوضـع الضريبي والمالي لدافعي الضرائب (21).

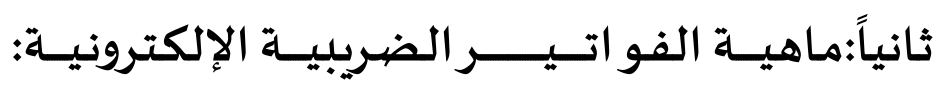

كمئ تُعد منظومـة الفـاتورة الإلكترونية إحدى مشروعات تطوير مصلحة الضـرائب المصرية وميكنتها، كما أن هذه المنظومـة الجديدة تعد من أهم مشروعات التحول الرقمى فى الدولة، مما يسهل عمليات التبادل التجاري بين الثركات بصـورة رقميـة تواكب أحدث التطورات التكنولوجية العالمية فى هذا المجال، وتضـاهى أفضل الممارسات العالمية فى العديد من الدول المتطورة فى العمل الضريبى (22). 
كعِ وتعرف الفاتورة الالكترونية بأنها نسخة إلكترونية من الفاتورة الورقية التقليدية، بمعنى أنه يتم إنشاؤها، وإرسالها وتلقيها بشكل إلكتروني بواسطة برنامج إلكتروني، كما أنها تعتبر حل منخفض التكاليف مقارنة مع عملية إعداد الفواتير بثكل يدوى أو ورقى، خاصة للشركات الصغيرة والناشئة اللتين لا تتوفر لديها ميزانية كبيرة(23). كعِ ويعرفها الباحث بأنها، مستند رقمي يثبت معاملات بيع السلع والخدمات ولهذا المستت مكونـات وخصـائص، ويتم إعداده والتوقيع عليه إلكترونيًا، وإرسـاله واستلامه من خـلال منظومـة الفواتير الإلكترونيـة وبمعرفة الممول، كمـا يـتم مراجعته والتحقق منـه لحظيًا من جانب مصلحة الضرائب.

كع تتميز منظومة الفواتير الإلكترونية بخصائص عديدة، أول هذه الخصائص هو وجود رقم فريد لكل فاتورة، ويسىى هذا بالرقم التعريفي Uuid ويختلف عن رقم الفاتورة الداخلي للشركة، أما ثاني هذه الخصائص فهي وجود شكل ومحتوى موحد لكل فاتورة داخل المنظومة مع التأكيد على أن شكل الفاتورة لن يتغير داخل الثركة. حيث تقوم برامـج تخطيط المؤسسة ERP بإرسال البيانات التي تحددها مصلحة الضرائب إلى منظومة الفاتورة الإلكترونية وتقوم واجهة برمجة التطبيقات API بنقل بيانات الفاتورة بصيغة JSON أو XML دون نقل شكل الفاتورة. كما تتيح أيضًا تكويد موحد للسلع والخدمات، وتثمل الفواتير توقيعا إلكترونيًا مما يضمن تأمينًا كاملاً لبيانات الفواتير وإثبات الحجية القانونية على مستخدمي المنظومة طبقاً للقانون رقم 15 لسنة 2004م بتنظيم التوقيع الإكترونى. وترسل المنظومة إخطارات لحظية لكل من البائع والمشتري لمشاركتهم بيانات الفواتير ، حيث تتم مشاركة ، SMS الفواتير بكافة الوسائل التي تتيحها المنظومة، وهى خدمات الويب ،ورسائل قصيرة ورسائل بريد إلكتروني، وتطبيقات الموبايل. كما يمكن أيضا - باستخدام المنظومة - حفظ بيانات الفاتورة واستعراضها وطباعتها.

كما تتيح المنظومة خيار ربطها بأي من نظم تخطيط موارد المؤسسة. ويتم تحقيق هذا التكامل باستخدام مجموعة من واجهات برمجة التطبيقات APIS التي توفّرها الثركة المنفذة للحل الفني، كما توفر مصلحة الضرائب أيضًا منصة لشرح خطوات التكامل وواجهاته(SDK). 
كع وتجدر الإثارة هنا إلى أن مصلحة الضرائب لا تزال تعمل على ربط منظومة الفاتورة الإلكترونية بالإقرار الإلكتروني، ومن المتوقع إتاحة هذا التكامل في المراحل التالية للمنظومة. كعيعتيح منظومة الفاتورة الإكترونية إصدار الفواتير باللغتين العربية والإنجليزية، كما تسمح بتبادل الفواتير وإشعارات الخصم، وإشعارات الإضافة مع الأطراف والشركات الأخرى، كما تحفظ المنظومة لمستخدميها حق تعديل الفواتير بإصدار إشعارات خصم أو إضافة على الفاتورة أو إلغاء الفاتورة كليًا وإصدار فاتورة أخرى على أن يحدث هذا خلال الوقت المحدد قانونا للإلغاء، أما في حال وجود خطأ في فاتورة تم إصدارها سابقا فيتم التعديل عليها بإصدار إثعارات الخصم أو إثعارات الإضافة المرتبطة بالفواتير السابقة. كعا كما يمكن إصدار إشعارات مرتبطة بمجموعة من الفواتير بدلاً من فاتورة واحدة مع مراعاة ألا يتخطى مجموع مبالغ تلك الإشعارات مبلغ الفاتورة السابق إصدارها. تمكّن المنظومة مستخدميها أيضًا من إصدار إشعار بمبلغ دائن بشرط ألا يتخطى مبلغ الإشعار الدائن مبلغ الفاتورة المرتبط بها.

كمع أما عند الرغبة في إلغاء فاتورة بعد إصدارها فإن المنظومة تسمح للبائع بإلغاء الفاتورة الإككترونية خلال مدة يحددها القانون. وفي هذه الحالة يجب على البائع طلب إلغاء الفاتورة على المنظومة التي ترسل للمشتري إخطارًا بالإلغاء.

كمع بعد وصول إخطار للمشتري بالإلغاء يمكنه الموافقة أو الرفض على إلغاء المستند، فإذا وافق على الالغاء يلغى المستند وتصبح حالة الفاتورة على المنظومة(ملغاة)، وفي حالة رفض المشتري إلغاء المستتد لا يلغى المستند ويعتبر في هذه الحالة مستنداً صحيح على المنظومة. كيع يطلب نظام الفاتورة الإلكترونية الرقم الضريبي للمشتري- للتعاملات فوق حد معين يحده القانون- لإصدار الفاتورة، وفي حال التعامل مع عملاء غير مسجلين ضريبيًا يجب استخدام الرقم القومي للمشتري بدلاً من الرقم الضريبي . 
كعِومن خصائص منظومة الفواتير الإكترونية أيضًا إنشاء ملف رقمي للممولين ليتم التعامل من خلاله مع المصلحة، ويتم ربط هذا الملف الرقمي ببيانات الممول المسجلة لدى المصلحة؛ على سبيل المثال رقم التسجيل الضريبي، اسم الثركة، العنوان الرئيسي. ويرتبط بكل شركة مفوضين معتمدين، ويمثل نظام تخطيط الموارد المؤسسي (ERP) أحد هؤلاء المفوضين، والذي يُعتمد بطريقة آمنة لتبادل المستتدات مع المصلحة. كما أنه يتم توقيع كل

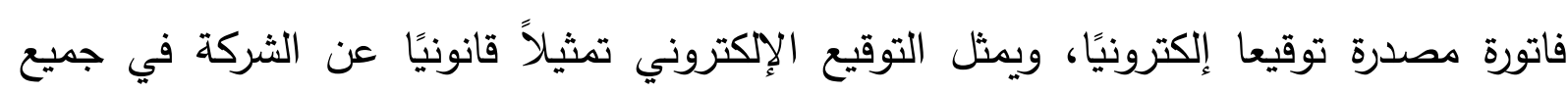

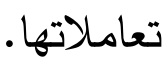

كعِ لا تلخل البضائع المستوردة من خارج جمهورية مصر العربية ضمن منظومة الفاتورة الإكترونية؛ لأن مصدر الفاتورة من خارج جمهورية مصر العربية، لكن في حالة إعادة بيع تلك البضائع لأشخاص أو شركات داخل الجمهورية فتخضع كمعاملة لمنظومة الفاتورة الإكترونية. كع متعتبر جمهورية مصر العربية هي الدولة الأولى بالثرق الأوسط التي تطبق منظومة الفاتورة الإكترونية والتى ترتكز على إنشاء نظام مركزي إلكتروني لتلقي ومراجعة واعتماد ومتابعة فواتير البيع والثراء للتعاملات التجارية بين الثركات من خلال التبادل اللحظي لبيانات الفواتير بصيغة رقمية دون الاعتماد على المعاملات الورقية لحصر المجتمع الضريبي.

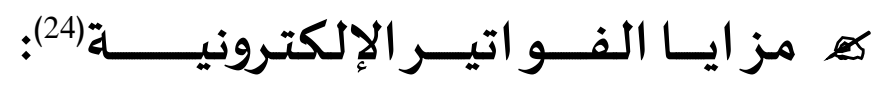

- تساعد على الحد من كمية الأوراق المستعملة للتوثيق أو تخزين معلومات المعاملة. - يستطيع البائعون أن يتخلصوا من كثير من العمليات اليدوية مثل( الطباعة، والإرسال البريدى، والتوثيق، والتخزين، والتوفيق بين الفواتيـر الورقية). - تتيح معايير الفوترة الإلكترونية نقل البيانات بصورة سريعة وفعالة، ويحد بذلك من الفترة الزمنية التى تستغرقها دورة عملية إعداد الفاتورة. - تحديث حالة الفاتورة، والتحويل السريع للفواتير لموافقة الدافعين عليها، ونظم الإدارة السريعة لحل النزاعات تتتج خدمة أفضل للعملاء. 
- يتلقى الدافعون على تحديثات منتظمة عن حالة الفاتورة وتوقيت السداد، مما يمكنهم من تقدير التدفق النقدي الخارجي بتيقن، ويساعدهم بذلك على إنجاز أفضل وإدارة فاعلة لرأس المال

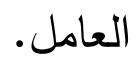
- المقدرة على إعطاء تخفيضات على السداد الفورى. - يعطى بعض الموردين تخفيضات إذا دفعت الفواتير التى أصدروها بسرعة، وكثير من العملاء يرغبون فى الاستفادة من هذه التخفيضات.

كيً يُظهر تنوع الأدوات التي تستخدمها الدولة لضم قدر ما تستطيع من القطاع غير الرسمي،أهميته للإيرادات العامة للدولة التي تتمحور أساسًا حول الإيرادات العامة، بما يجعل كُل زيادة في الحصيلة الضريبية تُشفر عن خفض مُعتبر في العجز الكُلي للموازنة. وتزداد هذه الأهمية في ضوء ضخامة الاقتصاد غير الرسمي نسبة إلى الناتج المحلي الإجمالي، مما يجعل كُل جُهد لضم شريحة منه ولو بسيطة، فائدة ضخمة للاقتصاد المصري(25). كعِ وتعمل منظومة الفاتورة الإكترونيـة على توسيع القاعدة الضرببية، وإرساء دعائم العدالة الضريبية، وحصر المجتمع الضريبي بشكل أكثر دقة، ودمج الاقتصاد غير الرسمي في الاقتصاد الرسمي والذى أصبح أحد شواغل الدولة في فترة ما بعد برنامج الإصلاح الاقتصادي. حيث بدأت تُشكل المُبادرات وتُعيد صياغة القوانين لتحويله إلى الرسمية، ولعل أبرز الجهود في ذلك المجال هي مُبادرة الثمول المالي التي أطلقها البنك المركزي بهدف مد التغطية المصرفية لعدد أكبر من الأعمال بما يضمها إلى القطاع الرسمي. من جانب آخر صدر قانون تنمية المشروعات المتوسطة والصغيـرة رقم 152 لسنـة 2020م الذي قدم صياغة جديدة لمفهوم الأعمال الصغيرة والمتوسطة تعتمد على حجم الأعمال إضافة إلى المفهوم الذي قدمه القانون القديم 141 لسنة 2004م مُعتمدًا على معيار رأس المال وعدد العاملين، علاوة على مجموعة ضخمة من الحوافز الضريبية وغير الضريبية تُساعد في ضم شريحـة أخرى من القطاع غير الرسمي. ولم تتوقف جهود الدولـة على هذا المستوى الكُلي بل ذهبت إلى مُستويات جُزئية أدق، مثل إعادة تقديم المنظومتين الضريبية والجمركية بشكل يُحكم الرقابة بما يدعم الجهود التحفيزية السابقة(26). 


\section{الاطبسب الثـاني

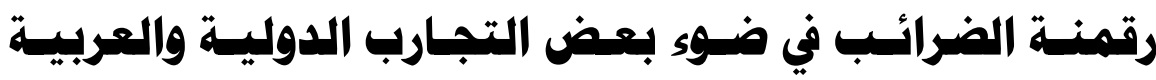

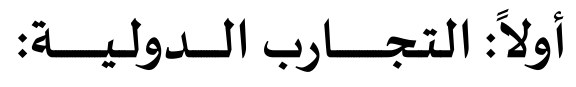

كع تتفاوت تجارب بلدان العالم في التحول الرقمي في عمليات الموازنة العامة، حيث سبق عدد من بلدان العالم المتقدم بلدان العالم النامية في مثل هذه التحولات منذ سنوات. فعلى سبيل المثال تم رقمنة كافة المدفوعات الحكومية المرتبطة بالتحويلات الاجتماعية في الولايات المتحدة الأمريكية منذ عام 2013م. كما حققت بلدان متقدمة أخرى إنجازات ملموسة في هذا الصدد حيث لا تتجاوز نسبة المدفوعات الحكومية غير الرقمية في كل من أسبانيا وإيطاليا نسبة 10 في المائة حاليًَا (27)

كها ع كذلك تقوم الآن دول مثل المملكة المتحدة وإستراليا وروسيا بتحصيل الضرائب المفروضة على الدخل والثركات على الفور من خلال أنظمة الرواتب الإلكترونية والفوترة الإكترونية، في السياق ذاته، تمكنت بعض الدول مثل المملكة المتحدة من معالجة التهرب الضريبي من خلال الحلول الرقمية، حيث تستخدم إدارة الجمارك البريطانية تقنية البيانات الكبيرة لاكتشاف السلوك الاحتيالي للمستوردين على الحدود، وهو ما ساهم في زيادة الحصيلة الجمركية السنوية بنسبة تصل إلى(1-2) في المائة من الناتج المحلي الإجمالي وفق بعض التقديرات. كما ساعد التحول الرقمي على زيادة نسبة مشاركة المشروعات الصغيرة والمتوسطة في نظم المشتريات الحكومية في المكسيك بنسبة 20 في المائة خلال عام 2018م مقارنة بالنسبة المسجلة عام (28) 2017

كع من جانب آخر، هنالك العديد من النماذج والتجارب العالمية الرائدة على صعيد رقمنة المالية العامة في الدول النامية. ففي الصين تتمكن الحكومة من خلال مراجعة أنظمة الفوترة الإلكترونية واستخدام تقنيات البلوكثين (*)من التحقق من امتثال الثركات الضريبة القيمة المضافة ومحاربة التهرب الضريبي. فيما تتوفر تجربة رائدة لرقمنة المالية العامة. 
كهِ تعدُ الهند أولي الدول فى استخدام تكنولـوجيا البصمة البيوميترية، حيث تبنت الحكومة في عام 2009م مشروع الهوية البيومترية الوطني المعروف باسم( Aadhaar)، وهو أكبر مشروع للهوية الوطنية على مستوى العالم، حيث بلغ عدد مسجلين في النظام حوالى 1,2 مليار مواطن (99 في المائة من سكان الهند، يشكلون نحـ 15 في المائـة من سكان العالـم) (29). كعِ يستند النظـام إلى اثنى عشر رقمًا مدعومًا بالمصادقة من خلال البصمة البيومترية التي توفر إثباتًا آمنًا وفريدًا للهوية من خلال فحص بصمة الإبهام أو القزحية عند نقاط تقديم الخدمة ومرتبط برقم الهاتف النقال، رغم كون هذا النظام قد تم تبنيه بهدف زيادة مستويات الثمول المالي وزيادة عدد الحسابات المصرفية التي زادت بنحو 240 مليون حساب مصرفي في أشهر قليلة من تدشين النظام إلا أنه قد مكن الحكومة أيضًا من زيادة كفاءة نظم التحويلات الاجتماعية ودفع المعاشات، حيث يتم من خلال هذا النظام توصيل مدفوعات برامج الدعم لاسيما دعم السلع الغذائية والوقود المنزلي مباشرة إلى الحسابات المصرفية للمستحقين المرتبطة بنظام الهوية البيومترية في أي مكان في الهند، بما فيها الأماكن التي لا تتوفر فيها فروع بنكية أو ماكينات للصرف الآلي عبر الهاتف المحمول.

كما مكن النظام الحكومة من التنقيح الدوري لقوائم المستفيدين من التحويلات الاجتماعية لمنع الازدواجية أو وصول الدعم لغير المستحقين، كما تم مؤخرة إلزام المواطنين بربط إقراراتهم الضريبية بنظام الهوية الوطنية. في ضوء نجاح النظام الخاص بالهوية الوطنية للأفراد تسعى الحكومة حالية إلى تطبيقه على مستوى الثركات. يرتبط بالنظام حاليًا أكثر من مليار حساب مصرفي وهاتف محمول وتم من خلاله تنفيذ معاملات بقيمة 12 مليار دولار وحققت الحكومة جراء تفعيل هذا البرنامج وفورات كبيرة على صعيد الموازنة العامة للدولة بلغت أضعاف كلفة تطبيقه ، حيث تثير التقديرات إلى أنه وفر للحكومة نحو 10 مليار دولار تقريبًا خلال عامي 2017 و 2018م، فيما بلغت كلفة تطبيقه 
يشار إلى أن تطور نظم الدفع الإكتروني في الهند قد ساهم بثكل كبير في نجاح التجربة ، حيث شهدت تطورًا ملحوظة في الآونة الأخيرة وهو ما يتوقع معه أن يصل حجم سوق الدفع الإلكتروني في الهند إلى 500 مليار دولار سنوية عام 2020 وهو ما سوف يؤهل سوق الدفع الإلكتروني إلى أن يساهم بنحو 15 في المائة من الناتج المحلي الإجمالي في ذلك الوقت ـ كما ساهم تعاون كافة الجهات والدعم السياسي الكبير للمشروع في نجاحه.

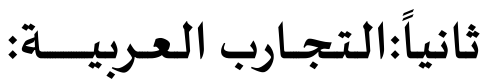

كع حرصت الحكومات العربية في إطار خططها القومية الهادفة إلى التحول الرقمي ومساعيها للإصلاح المالي إلى التحول نحو رقمنة المالية العامة. وقد حقق العديد من الدول العربية نجاحات ملموسة في هذا الإطار .

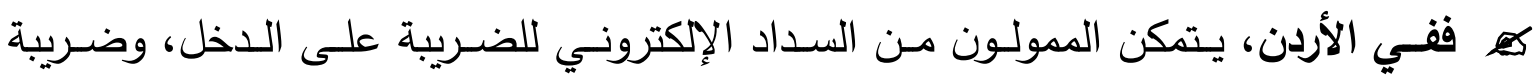

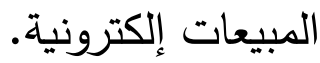

كهي وفي الإمـارات، تبنت وزارة المالية منظومة من البرمجيات وبوابات الدفع الرقمية بوسائط الاتصال المختلفة لتحصيل رسوم خدمات إيرادات الحكومة الاتحادية ببطاقات خاصـة مسبقة الدفع للارتقاء بعمليات تقديم الخدمات العامة في إطار منظومة الدرهم الإلكتروني التي تم تشينها في عام 2001. يتميز الجيل الثاني لمنظومـة الدرهم الإكتروني الذي تم تثغيله في عام 2011 بتكامله مع شبكات ووسائل الدفع العالمية بمنصات نظم مهيأة لذلك، تتسم بالمرونة وبما يتماشى مـع تطبيقات خدمات الحكومة الإلكترونية وقابلة للتشكيل والتطوير اللامحدود لتطبيقات خدمات السداد على الإنترنت والهاتف المحمول والتحصيل الإلكتروني. يستخدم الدرهم الإلكتروني حاليا لسداد مقابل أكثر من 5000 خدمة حكومية في الوزارات والمؤسسات الاتحادية والمحلية والقطاع

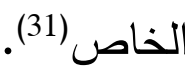

كعا ت تتميز منظومة الدرهم الإكتروني بتعدد أنواع بطاقاتها، وتوفر رسوم خدمات مخفضة، لا تتطلب حساب بنكية، جميعها مدفوعة سلفاً، قابلة لإعادة التعبئة وتعتمد على السحب من الرصيد، المدفوع أو المغطى ببطاقات الأتمان، بطريقة ذكية وآمنة، منذ إطلاق الجيل الثاني لمنظومة 
بطاقات الدرهم الإلكتروني ، تم تقديم حوالي 100 مليون خدمة إلكترونية بقيمة إجمالية بلغت 21,66 مليار درهم حتى نهاية عام 2015.

كهِ في تونس، يسمح للممولين بسداد ضريبتي القيمة المضافة وضريبة دخل الثركات إلكترونية، وفي السعودية، تم تطوير منصة " سداد " للدفع الإلكتروني بما يخدم الأفراد والثركات والقطاع الحكومي من خلال تشغيل بنية تحتية تتسم بالكفاءة والأمان والتوافق مع أفضل الممارسات. يتم من خلال هذه المنصة الدفع الإلكتروني الضرائب القيمة المضافة . كهِ في السـودان، يعتبر زيادة أعداد دافعي الضرائب من أبرز التحديات التي تواجه السياسة المالية التي ترتكز بشكل كبير على الإيرادات الضريبية التي تسهم بنحو 83 في المائة من إجمالي الضرائب،في هذا السياق، تشير بيانات وزارة المالية والتخطيط الاقتصادي، إلى أن عدد المسجلين لديها كدافعي ضرائب يعتبر محدودة مقارنة بعدد السكان الذي يقترب من 41 مليون نسمة(32). كعَ وفي إطار سعي وزارة المالية والتخطيط الاقتصادي للاستفادة من التقنيات المالية الحديثة، تم تطبيق نظام التحصيل الإكتروني في السودان منذ عام 2015 باستخدام نظام " أورنيك 15 الإلكتروني" (33). كعِ كما تم إطلاق خدمة "علينـا" التي تعتبر أول خدمة للفوترة والسداد والتحصيل الإكتروني، تعمل الخدمة على ربط أنظمة المؤسسات المالية، والقطاع الخاص، والتجار بأنظمة الربط الإلكتروني، مع إمكانية سداد رسوم المؤسسات عبر نوافذ عدد من البنوك والصرافات الآلية ونقاط البيع والهواتف الذكية التي تعمل في مجال التحصيل الإلكتروني في السودان، كما يمكن القيام بالسداد عبر الأنظمة الإلكترونية، وبطاقات المحفظة الإلكترونية، وبوابة الرسائل القصيرة، ومركز الاستعلام الإلكتروني، فضلا عن توفير آلية سهلة وسريعة التحويل الأموال بين الأفراد. ساهم النظام في ضبط عمليات التقدير الجزافي للضرائب وساعد على زيادة عدد الممولين بشكل ملموس. وفي المغـرب، اتجهت الإدارة العامة للضرائب إلى تطوير خدمة سداد الضرائب عبر الإنترنت لتمكين الممولين من الإقرار والدفع الإلكتروني لضرائب المبيعات والثركات والدخل. كما تبنت موريتـانيا نظامة إلكترونية للتخليص الجمركي ساعد في خفض الوقت اللزم لإنجاز مثل هذه المعاملات (34) - (34) 
1- توجد ضـرورة حتمية لإصـلاح التشربعات الضرببية وتحسين نظم السياسات الضريبية من خلال ميكنة النظام الضريبي بإدخال بنية تكنولوجية حديثة تسهم في تكوين قواعد بيانات متكاملة تشمل المعلومات الكمية والمالية بمصلحة الضرائب. 2- تعاني الإدارة الضريبية المصرية من ضعف الإمكانيات المادية والبشرية وعدم فعالية التدريب الضريبي وعدم انسيابية العلاقات بين مختلف المستويات الإدارية وعدم الالتزام بمفاهيم الجودة .. الخ ، الأمر الذي كثف عن وجود بعض القصور في مواد القانون ولائحته التنفيذية. 3- تتجسـ أهمية التحول الرقمي في تحديث منظومة الإدارة الضريبية وتيسير الإجراءات على الممولين، على النحو الذي يسهم في تحفيز الاستثمار وتشجيع المستثرين على التوسع في أنشطتهم، وتحقيق العدالة الضرببية وضبط المجتمع بشكل أكثر دقة، وتحصيل حق الدولة. 4- تستهدف تطبيق منظومة الفواتير الضريبية الاكترونية القضاء على السوق الموازية والاقتصاد غير الرسمي، وتحقيق مبدأ تكافؤ الفرص والعدالة بين الثركات العاملة فى السوق المصرية، وتسهيل وتسريع الإجراءات الضريبية.كما تعدُ هذه المنظومة خطوة هامة على طريق التحول الرقمي لتحقيق رؤية مصر 2030م، وخطوة رئيسية لتطوير المنظومة الضريبية، وفع كفاءة الفحص الضريبي. 5- يسهـم تقديم الإقرارات الضريبية الاكترونيـة في إنهاء حالات التكدس من خلال عدد مرات تردد الممولين والمسجلين على مأموريات الضرائب، وكذلك تخفيض تمكين مأموري الضرائب من القيام بمهامهم الأساسية في فحص الملفات الضربيية خاصة ذات القيم الكبيرة للحد من

$$
\begin{aligned}
& \text { التهرب الضريبي. } \\
& \text { ثانيًا: التوصيـيــات: }
\end{aligned}
$$

1- إنشـاء جهة متخصسصـة معنية بغرض تسريع وتيرة التحول الرقـي في القطاعات كافة بما يضمن زيادة مستويات الإنتاجية والتنافسية للقطاعات الاقتصادية المختلفة. 
2- توفيـر بنيـة تحتيـة تكنولوجيـة، تساهم في مواكبة التطورات المحيطة بها من كل جانب، حتى تصبح جزءاً من التطور العالمي، إلى جانب دراسة التعديلات المطلوبة في التشريعات المصرية، في ما يتعلق بتحديد حق الدولة المصرية، في فرض الضريبة على هذا النشـاط وحق الإدارة الضريبية فى الحصول على المعلومات، وكذلك الحوافز المطلوبة لجذب الشركات العاملة في مجال الاقتصاد الرقمي. 3- تعزيز المهارات الرقمية لدى الأفراد والثركات، حيث من الضروري تحسين مهارات وقدرات الأفراد والثركات الرقمية في الدول العربية من أجل مواكبة مستجدات حقبة الثورة الصناعية

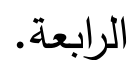
4- ضـرورة وجـود وتفعيل مهام المجلس الاستثاري الضريبي بشأن الإشراف والرقابة على أعمال الإدارة الضريبية ومدي التزامها بالقوانين والتشريعات الحاكمة. 5- العمل على تكثيف الجهود الإعلامية لمصلحة الضرائب المصرية، من خلال مراكز الدعم الفني والاتصال، وورش الععل واللقاءات والندوات التى يتم تنظيمها مع كل الممولين، الأمر الذى يسهم فى تأهيل المجتمع الضريبي لمواكبة التطوير. 


\section{المراجع العربية والأجنبية}

(1) محمود عبدالـــــــمن كامل مكاوي. معوقات التحول الرقمي بالمشروعات الصغيرة والمتوسطة في مصر "دراسة استكثافية".

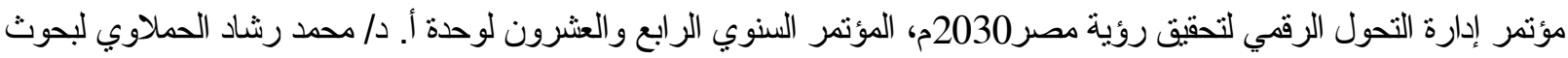

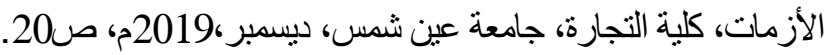

(2) Juswanto \& Simms, Wawan, Rebecca:Fair Taxation In The Digital Economy, ADB Institute, Policy Brief, No. 5, December,2017, P1.

$$
\begin{aligned}
& \text { (3) عبدالوهــاب غـنيم. التحول الرقمي ورؤية مصر 2030. مؤتمر إدارة التحول الرقمي لتحقيق رؤية مصر2030، المؤتمر } \\
& \text { السنوي الرابع والعشرون لوحدة أ. د/ محمد رشاد الحملاوي لبحوث الأزمات، كلية التجارة، جامعة عين شمس، ديسمبر،2019م، }
\end{aligned}
$$

(2) Hallzhieva, Eli: Impact of Digitalization on International Tax Matters (Challenges And Remedies The Taxes Committee), European Parliament, February, 2019, P14.

(3) Nazarov \& Other, M. A: Digital Economy: Russian Taxation Issues, International

Scientific Conference "Global Challenges and Prospects of The Modern Economic

Development", The European Proceedings of Social \& Behavioral Sciences.2019, P1274.

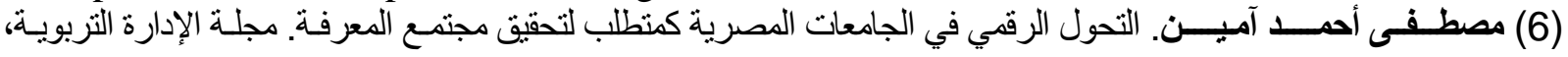

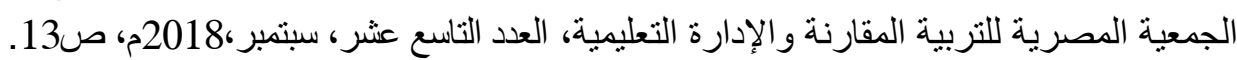

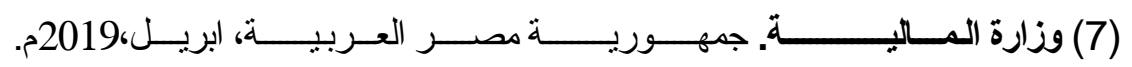

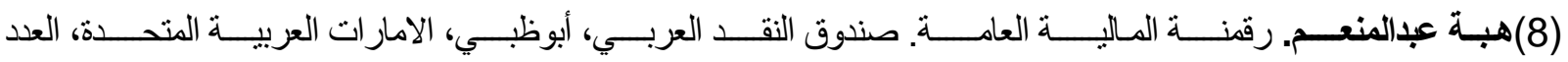

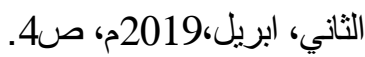

(9) آمسـل علي إبـراهيم. دور التحول الرقمي في دعم الإيرادات الضريبية (مع إثــارة خـاصـة للاقتصساد المصري). مجلة

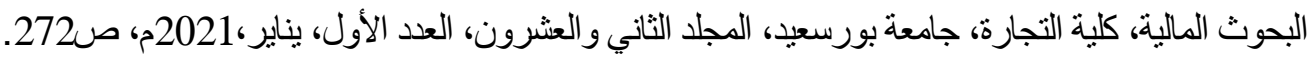

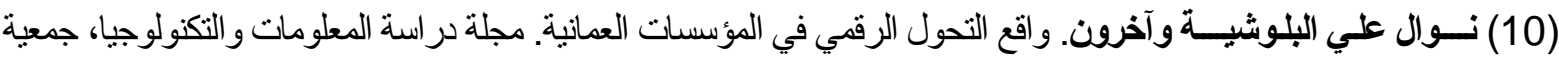

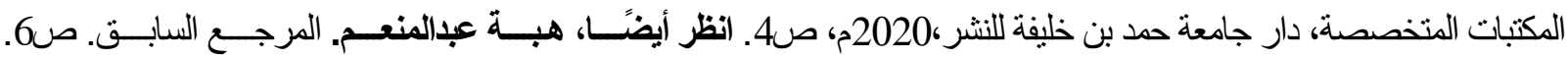

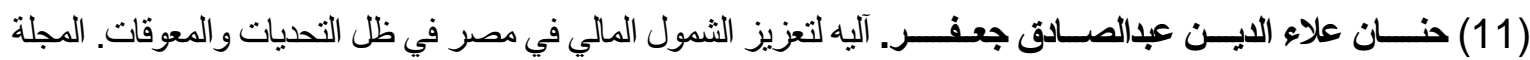

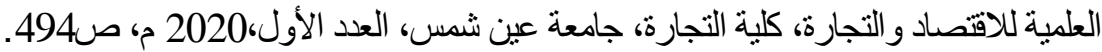

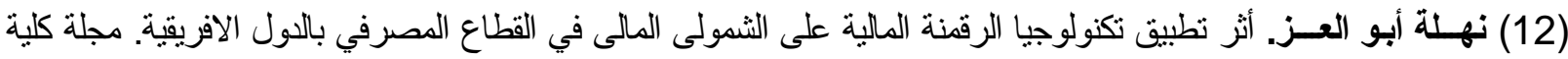

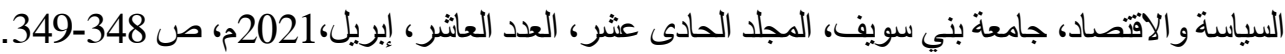

(13)Sanjeev Gupta Et Al:"Public Finance Digitization”, IMF, March,2018.

(14)OECD:“Innovative Government: Case Study: India Aadhaar”,2018.

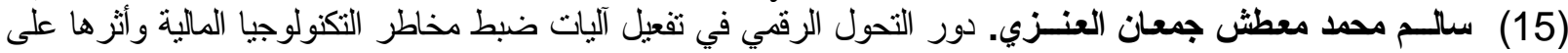

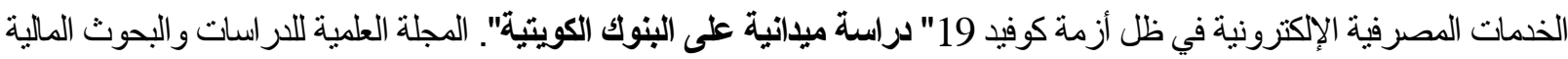

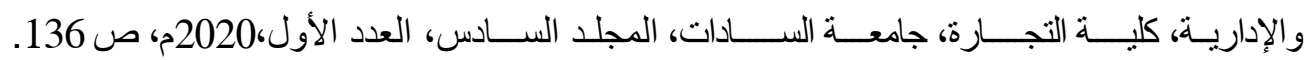

(16) الوليد طلحة، سفيـان قعلول. الاقتصاد الرقمي في الدول العربية "الواقع والتحديات". صندوق النقد العربي، أبو ظبي،

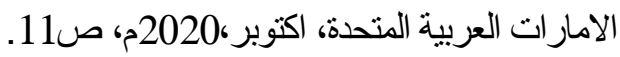

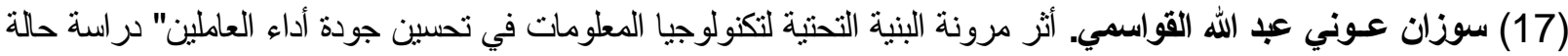

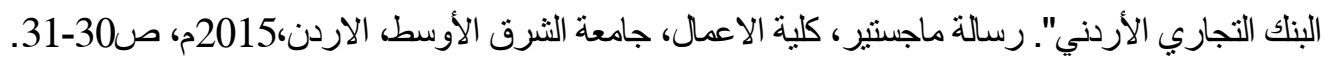

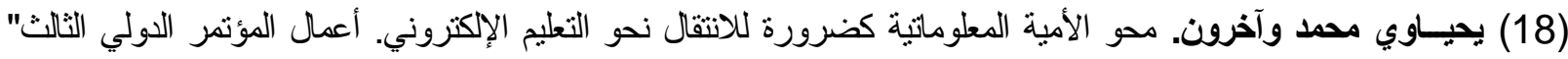

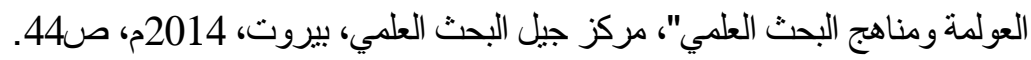




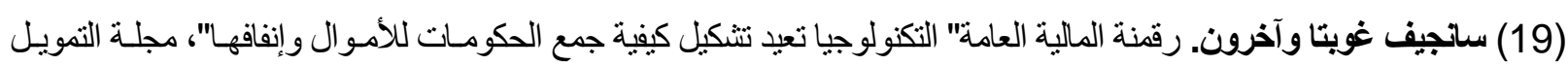

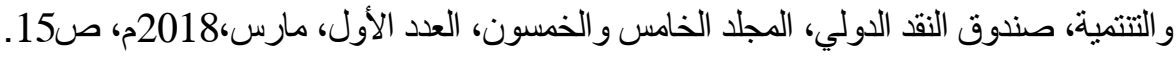

(1) The Doing Business, Comparing Business Regulation In 190 Economies, World Bank Group, 2020,P4.

(*) قانون الإجراءات الضريبية الموحد والصادر برقم 206لسنة2020م هو أحد أهم القوانين الضريبية التي صدرت في

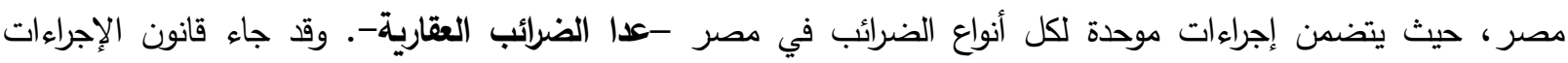

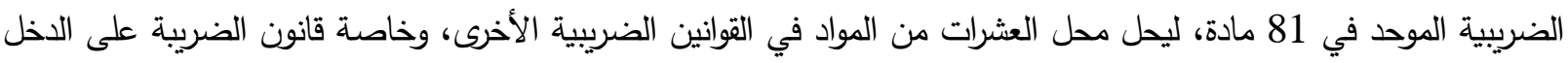

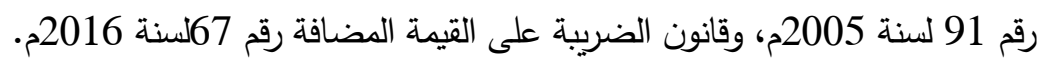

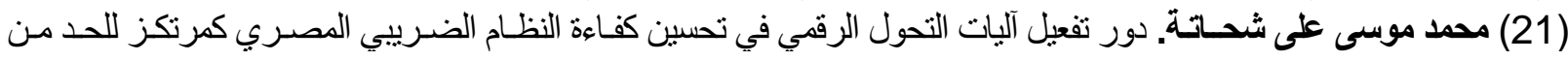

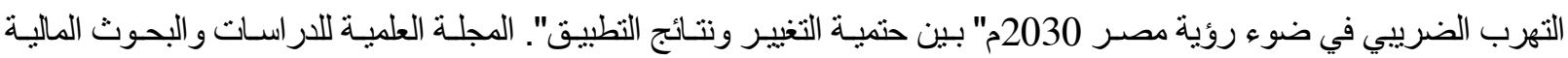

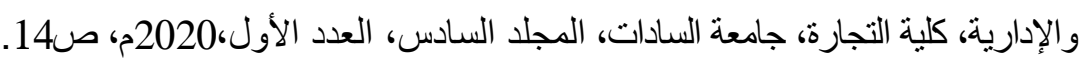

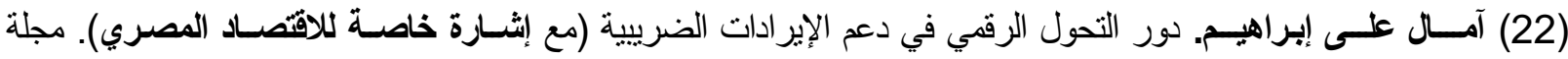

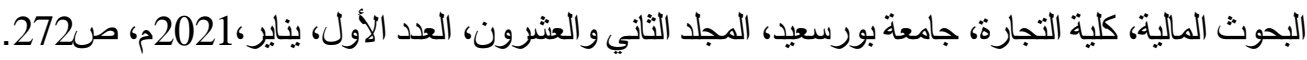

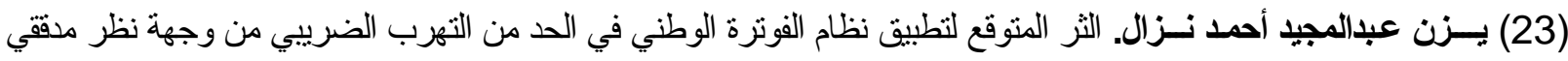

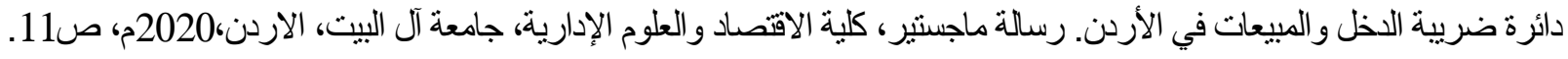

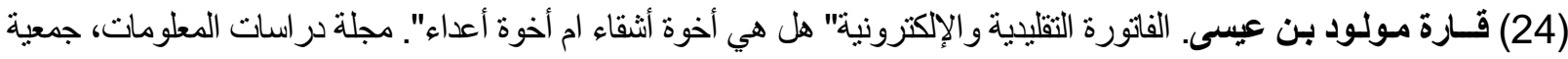

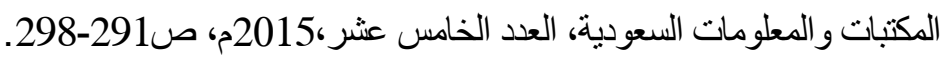

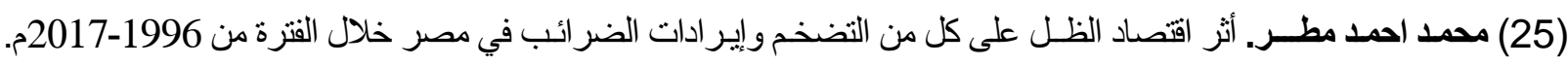

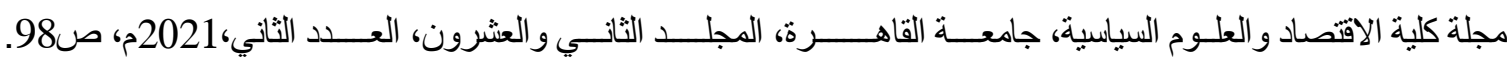

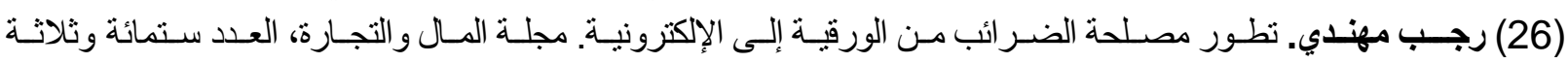

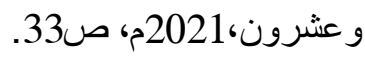

(27) Gaspar. V, Verdier G: "The Digital Gamble: New Technology Transforms Fiscal Policy", April,2018.

(28)Yolandat . T, Wright N: The future of public procurement in the era of digitalization", World Bank,2018.

(*) تعرف تقنية البلوك تثين أو سلسلـة الكتـل، بأنها أكبر قاعدة بيانات رقية آنـة، شفافة، فائقة السرعة، منخفضة التكلفة، لا

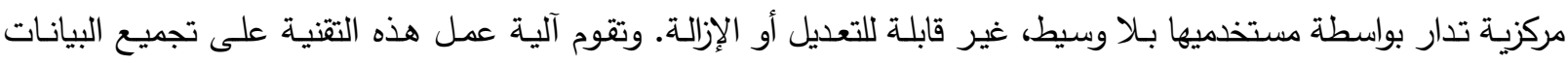

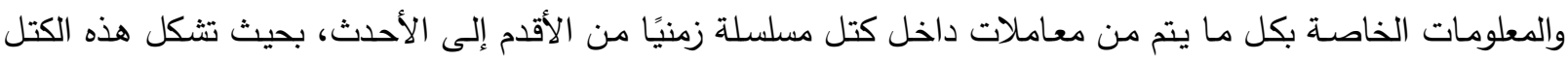

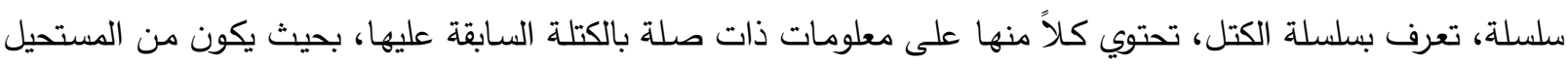

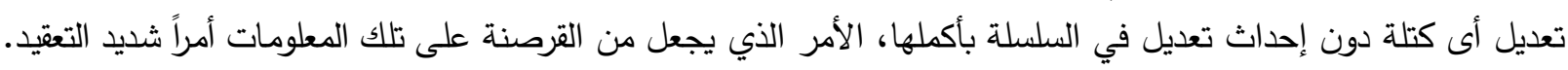

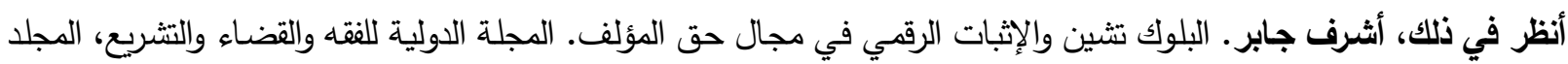

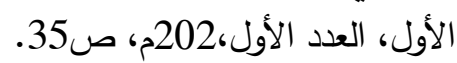

(29) OECD: “Innovative Government: Case Study: India Aadhaar”,2018.

(30) Sanjeev Gupta et al: Op. cit.

$$
\begin{aligned}
& \text { (31) وزارة المـاليــة. دولة الإمار ات العربية المتحدة.2019م. }
\end{aligned}
$$

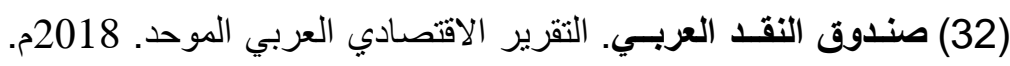

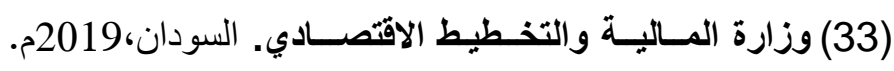

$$
\begin{aligned}
& \text { (34) وزارة المــاليـــة المملكة المغربية. 2019مة وزليط. }
\end{aligned}
$$

